\title{
EL EMPRENDIMIENTO SOCIAL Y EL EMPLEO DE CALIDAD
}

\author{
Concha Guil Marchante \\ Departamento de Organización de Empresas \\ Facultad de Ciencias del Trabajo \\ Universidad de Cádiz \\ M. Socorro Montoya SÁnchez \\ Departamento de Economía General \\ Facultad de Ciencias del Trabajo \\ Universidad de Cádiz
}

DOI: 10.1387/lan-harremanak.15409

\section{ABSTRACT}

Existe un interés a nivel internacional de promover proyectos de desarrollo social en donde las empresas sociales tienen un importante papel en la creación de empleos en condiciones dignas (Díaz, Marcuello y Marcuello, 2012), en este sentido también se pronuncia la Unión Europea en su estrategia Europa 2020. Los estudios sobre emprendimiento social a principios de este siglo, ya ponian de manifiesto los efectos "desproporcionadamente" efectivos de las empresas sociales en la creación de puestos de trabajo (Harding, 2004); sin embargo, la creación de empleo en los años de la actual crisis económica han suscitado importantes críticas en cuanto a la calidad del trabajo generado. En este contexto, se plantea el objetivo de este trabajo que es determinar el tipo de empleo creado a través del emprendimiento social en la Comunidad Autónoma Andaluza en los últimos años. Para ello, se analiza la noción de empleo de calidad siguiendo las directrices propuestas por la Organización Internacional del Trabajo y la Comisión Europea (Somavia, 2004; European Comision, 2001), y en función al criterio de empleo de calidad, se estudia el concepto de empleo 
a tiempo parcial desde el punto de vista normativo y estadistico, con el fin de acotar de forma cuantitativa el valor de este tipo de trabajo. En paralelo, se examina el empleo creado por el emprendimiento social en el territorio andaluz, estableciéndose un análisis comparativo por tipos de trabajos: indefinidos, temporales y a tiempo parcial. El resultado de la creación de empleo en los últimos años ha ido en detrimento del empleo de calidad, han aumentado los empleos de jornadas reducidas o muy reducidas que obstaculizan un nivel de renta sostenible para muchas familias.

Palabras clave: Economía social, emprendimiento social, empresas de economía social, empleo de calidad, tiempo parcial.

There is international interest in promoting social development projects where social enterprises have an important role in creating jobs in decent conditions (Diaz, Marcuello and Marcuello, 2012), in this sense also pronounced the European Union as a Europe 2020 strategy studies on social entrepreneurship at the beginning of this century, as was evident from the effects "disproportionately" effective social enterprises in creating jobs (Harding, 2004); However, job creation in the years of the current economic crisis have raised substantial criticism as to the quality of the generated work. In this context, the aim of this work is to determine the type of employment created through social entrepreneurship in the Autonomous Community of Andalusia in recent years arises. To do this, the notion of quality employment is analyzed according to the guidelines proposed by the International Labour Organization and the European Commission (Somavia, 2004; European Commission, 2001), and according to the criterion of quality employment, the concept is studied part-time employment from the point of regulatory and statistically, in order to limit quantitatively the value of this type of work. At the same time, the employment created by social entrepreneurship in Andalusia under review, establishing a comparative analysis by type of work: permanent, temporary and part-time. The result of job creation in recent years has been to the detriment of quality jobs, jobs have increased days reduced or very reduced impeding a sustainable level of income for many families.

Key Words: Social economy, social entrepreneurship, social economy enterprises, quality jobs, part time. 


\section{Introducción}

El emprendimiento social es un fenómeno en auge que surge con la esperanza de encontrar respuestas a los problemas actuales, sobre todo en tiempos de crisis. La diferencia entre el emprendimiento económico y el emprendimiento social radica en que éste último procura valor social sostenible (Harding, 2004, Guzmán y Trujillo, 2008) a través del desarrollo de oportunidades para el cambio social (Roberts y Woods, 2005; Martin y Osberg, 2007), en aquellos sectores en donde se identifica un equilibrio estable pero injusto que causa exclusión, marginalización o sufrimiento a determinados segmentos de la población. Para Chell (2007), todo emprendimiento conlleva un balance de comportamiento social y económico que va a permitir la generación de valor social y valor económico, si bien, la diferencia entre un emprendimiento de negocios y un emprendimiento social se establece en la forma en la que se genera dicho valor (Santos, 2012). La persona que emprende socialmente no actúa necesariamente motivada para generar remuneraciones materiales o monetarias para sí mismo, sino que tomando las mismas herramientas que existen en el sector privado, las aplica para resolver problemas sociales, siendo su propósito fundamental la creación de valor social para el bien público (Murphy y Coombes, 2009; Sullivan, Weerawardena y Carnegie, 2002; Moore, 2000).

La generación de valor social por parte de los emprendimientos sociales se produce con la búsqueda del progreso social mediante la eliminación de barreras que dificultan la inclusión, el apoyo y la ayuda a colectivos debilitados o que carecen de voz propia, y la mitigación de los efectos secundarios indeseables de la actividad económica, en definitiva, ayudando al beneficiario a obtener un valor que, por diversos motivos, habrían estado fuera de su alcance (Social Enterprise Knowledge Network, 2006, en Guzmán y Trujillo, 2008). Si bien todas las empresas sociales nacen con el fin de generar valor social, no todas comparten la meta de obtener retornos económicos, lo que da lugar a la existencia de empresas no lucrativas y empresas híbridas, que combinan la creación de valor social y económico, por tanto la empresa social también puede ser competitiva y generar beneficio propio, siempre que su orientación sea la consecución de su objetivo social (Rubio, Aragón, Nicolás y Pérez, 2014). 
La importancia del emprendimiento social radica en su impacto sobre el desarrollo económico y social, como manifestación de la actividad del emprendedor en la economía (Guzmán y Trujillo, 2008). En este sentido, el Observatorio de Emprendimiento Global del Reino Unido resaltó tras un estudio realizado en 2003, los efectos "desproporcionadamente» efectivos de los emprendimientos sociales en la creación de puestos de trabajo (Harding, 2004), y más recientemente, la Unión Europea en su estrategia Europa 2020 ponía de manifiesto el interés existente a nivel internacional en la promoción de proyectos de desarrollo social por el importante papel que las empresas sociales tienen en la creación de empleos en condiciones dignas (Díaz, Marcuello y Marcuello, 2012).

Por su parte, Melián y Campos (2010) ponen de manifiesto el grado de competitividad de las empresas de Economía Social (EES) en la creación de empleo en tiempos de crisis, contribuyendo al mantenimiento del empleo a través de dos tipos de iniciativas: el emprendedor social que constituye nuevas empresas sociales; y las empresas de capitales en crisis que se transforman en cooperativas de trabajo asociado para poder mantenerse en el mercado. Según estos autores los emprendedores sociales y las EES representan un instrumento apropiado para hacer frente a la actual crisis económica, enfocando el crecimiento empresarial hacia la inserción laboral y el desarrollo local.

Pero, ¿qué tipos de empleo generan las EES? ¿son empleos de calidad? En este contexto, esta comunicación pretende reflexionar sobre la contribución de las EES a la creación de empleo de calidad en un entorno de crisis económica que ha propiciado importantes críticas en cuanto a la calidad del trabajo generado, principalmente referidas al empleo a tiempo parcial. En este sentido se analiza el concepto de empleo de calidad, de empleo a tiempo parcial, y la evolución del empleo a tiempo parcial en Andalucía, así como su comparación con la evolución del empleo en Espańa y en las EES.

\section{El empleo de calidad en Espańa: la consideración conceptual y normativa del trabajo a tiempo parcial}

Para identificar un empleo de buena calidad, la noción debe contener características que aporten bienestar económico, social y psíquico, para lograr la satisfacción de las necesidades comúnmente aceptadas de los individuos (Farné, 2003; Van Bastelaer y Hussmann, 2000).

En el análisis del empleo de calidad uno de los indicadores más comunes es el estudio de la remuneración (Farné, 2003), si bien los investigadores insisten en añadir elementos fundamentales como la seguridad social, la seguridad en el empleo, el número de horas trabajadas a la semana, la estabilidad laboral, la asociación sindical, entre otras (Posso, 2010). 
Según la OIT $(1999,2006)$ el estudio del empleo decente debe concentrarse en el análisis de estadísticas básicas y la creación de indicadores que permitan evaluar los puestos de trabajo desde una perspectiva cualitativa, proponiendo las siguientes variables fundamentales: ingresos laborales, acceso a seguridad social, contratos laborales y la jornada de trabajo.

Uno de los elementos determinantes en el análisis del empleo de calidad para proporcionar bienestar depende, como se ha señalado, de la jornada de trabajo desempeñada por los trabajadores.

En este epígrafe nos hemos centrado en el análisis de las peculiaridades del empleo a tiempo parcial en España, ya que es un factor básico en la consideración de la calidad de las ocupaciones, y se trata de una cuestión muy debatida en los últimos años con motivo de la flexibilización del mercado de trabajo en los países desarrollados. Es en este contexto donde se analiza la conceptualización y la normativa del trabajo a tiempo parcial en Espańa.

\subsection{El concepto de trabajo a tiempo parcial}

El desarrollo del empleo a tiempo parcial en numerosos países ha coincidido con el proceso de diversificación de la fuerza de trabajo, y la flexibilización del mercado laboral demandada por las empresas desde los años setenta, tras la crisis del petróleo de 1973 (Sirvent, 2009). La implementación del empleo a tiempo parcial ha sido desigual dependiendo del sistema normativo y productivo de cada país. Los países del sur de Europa han mantenido unas tasas bajas de trabajadores a tiempo parcial, como es el caso de Grecia, Italia o España, en contraste con países como Dinamarca, Noruega o Gran Bretańa, cuya tasa supera la media de la Unión Europea para los 17 países de la zona euro UE-17 (eurozona) situado en 21,6 por ciento en 2012 (OCDE, 1998; OIT, 2011; OCDE, 2010; Eurostat, 2013). Los Países Bajos presentan la tasa de trabajo a tiempo parcial más elevada de la zona, constituyendo el caso más representativo de la implantación del contrato a tiempo parcial en Europa. Su uso se inició en los ańos setenta con la incorporación de la mujer al mercado laboral y continuó aumentando en las décadas de los años ochenta y noventa. Constituye una forma de trabajo elegida, a diferencia de otros países como España, donde la mayoría de trabajadores eligen este tipo de trabajo al no poder encontrar un trabajo a tiempo completo (Ramos y Blázquez, 2007).

El empleo a tiempo parcial es una forma atípica de empleo en la línea flexibilizadora del mercado de trabajo desarrollada en muchos países; siendo la flexibilidad contractual un conjunto de prácticas heterogéneas distintas del modelo básico de contrato indefinido a jornada completa. La flexibilidad laboral hace referencia a los modelos de contratación definida por períodos discontinuos y por jornada inferior a la normal — como el contrato a tiempo parcial — y los contratos de duración determinada, así como la reducción de costes de recluta- 
miento y de búsqueda de trabajadores, y la disminución de costes de resolución de los contratos para las empresas (Segura, Durán, Toharia y Bentolila 1991). Este nuevo modelo flexible será demandado por las empresas para la adaptación de las transformaciones del patrón productivo a los profundos cambios globales de los ańos ochenta (Segura et al., 1991).

A nivel europeo, los estudios comparativos sobre el trabajo a tiempo parcial tienen como primer obstáculo crucial la heterogeneidad del concepto. Los límites donde se enmarcan la mayoría de las definiciones oscilan entre 30 y 35 horas de trabajo, con lo cual los estudios comparativos pueden arrojar cifras infravaloradas si se establece un umbral común. La OCDE, recoge las estadísticas según la normativa de cada país (tabla 1), además realiza los cálculos del tiempo parcial con el corte de las 30 horas de trabajo para todos los países. Algunos países como Finlandia también consideran el umbral de 30 horas. Sin embargo, la mayoría de países europeos mantienen la delimitación de 35 horas semanales, con cierta flexibilidad, como es el caso de España. Por tanto, los límites del tiempo parcial en todos los países se encuentran entre las 30 y 35 horas de trabajo semanales.

Tabla 1

Participación del tiempo parcial en el empleo total. Países de la OCDE*

\begin{tabular}{l|cc|cc}
\hline \multirow{2}{*}{} & \multicolumn{2}{|c|}{2008} & \multicolumn{2}{c}{2012} \\
\cline { 2 - 5 } & $\begin{array}{c}\text { Definición } \\
\text { OCDE (30 h) }\end{array}$ & $\begin{array}{c}\text { Definiciones } \\
\text { nacionales }\end{array}$ & $\begin{array}{c}\text { Definición } \\
\text { OCDE (30 h) }\end{array}$ & $\begin{array}{c}\text { Definiciones } \\
\text { nacionales }\end{array}$ \\
\hline Alemania & 21,8 & 25,6 & 22,1 & 26,2 \\
Dinamarca & 17,8 & 24,2 & 19,4 & 25,4 \\
España & 11,1, & 12,0 & 13,8 & 14,7 \\
Francia & 12,9 & 16,9 & 13,8 & 17,9 \\
Grecia & 7,9 & 5,5 & 9,7 & 7,6 \\
Holanda & 36,1 & 34,3 & 37,8 & 35,8 \\
Italia & 15,9 & 14,3 & 17,8 & 17,0 \\
Noruega & 20,3 & 26,8 & 19,8 & 26,5 \\
Portugal & 9,7 & 11,9 & 12,2 & 14,3 \\
Gran Bretaña & 23,0 & 24,9 & 24,9 & 26,7 \\
EE.UU. & 12,8 & 17,4 & 13,4 & 19,4 \\
\hline Media OCDE & 15,6 & - & 16,9 & - \\
\hline
\end{tabular}

* La OCDE estima el tiempo parcial según criterio de cada país y según un punto de corte de 30 horas semanales.

Fuente: OCDE 2010, 2014. 
Si bien la definición del empleo a tiempo parcial difiere en cada país y, a menudo, es demasiado genérica y vaga, la mayoría de las definiciones se vinculan al patrón dado por los organismos internacionales, como el concepto dado por la OIT (1994) y por la Directiva Europea 97/81/CE sobre el trabajo a tiempo parcial. La Directiva Europea basa su definición de trabajo a tiempo parcial en el concepto elaborado por la OIT (1994) en cuanto al límite de la jornada y su comparabilidad con una jornada «normal» de trabajo. La Encuesta de las Fuerzas de Trabajo de la UE considera que los trabajadores a tiempo parcial son aquellos que se consideran como tales a la hora de encuestarlos.

La OIT establece en el preámbulo del Convenio núm. 175 sobre el trabajo a tiempo parcial la designación de un «trabajador a tiempo parcial» como "todo trabajador asalariado cuya actividad laboral, calculada sobre una base semanal o en promedio durante un periodo de empleo determinado, tiene una duración normal inferior a la de los trabajadores a tiempo completo comparable». Un trabajador a tiempo completo en situación comparable es el «que tenga el mismo tipo de relación laboral, que efectúa o ejerza un tipo de trabajo o profesión idéntico o similar, y que esté empleado en el mismo establecimiento o, cuando no haya ningún trabajador a tiempo completo en situación comparable en esa empresa, en la misma rama de actividad».

En los países de la OCDE, el método para la consideración del empleo a tiempo parcial se fundamenta en alguno de los siguientes enfoques: 1) La clasificación basada en la percepción del trabajador de su situación de empleo. 2) El establecimiento de un punto de corte (generalmente 30 o 35 horas por semana) basado en las horas de trabajo habituales. 3) La determinación de un corte comparable sobre la base de las horas efectivamente trabajadas durante la semana de referencia (OCDE, 2013).

En España, la regulación contempla la celebración de un contrato a tiempo parcial cuando se realiza un trabajo por la prestación de servicios durante un número de horas al día, a la semana, al mes o al año inferior a la jornada de trabajo de un trabajador a tiempo completo (Ley 12/2001, de 9 de julio). No obstante, la estadística para considerar un tiempo parcial no tiene en cuenta el concepto normativo. La metodología seguida por la EPA clasifica a las personas ocupadas ${ }^{1}$, atendiendo a la duración de la jornada en ocupados a tiempo completo y ocupados a tiempo parcial; para los ocupados a tiempo completo la jornada habitual semanal no puede ser inferior a 30 horas, y para los ocupados a tiempo parcial la jornada habitual de trabajo no puede ser superior a 35 horas. De tal manera que las personas que declaran trabajar a tiempo parcial pero cumplen

1 Según la EPA son "Ocupados las personas de 16 o más años que durante la semana de referencia han estado trabajando durante al menos una hora, a cambio de una retribución (salario, jornal, beneficio empresarial, etcétera) en dinero o especie. También son ocupados quienes teniendo trabajo han estado temporalmente ausentes del mismo por enfermedad, vacaciones, etcétera». 
más de 35 horas semanales se cuentan como trabajadores a tiempo completo; en cambio, las que declaran ejercer a tiempo completo pero efectúan menos de 30 horas se clasifican con los trabajadores a tiempo parcial.

La incertidumbre se plantea entre los trabajadores con jornadas laborales entre 30 y 35 horas semanales. En este tramo es donde se aplica el criterio subjetivo de cada trabajador en cuanto a su consideración a tiempo completo o parcial. Es éste un criterio personal y, es probable que el más flexible en la consideración del tiempo parcial.

\subsubsection{La jornada laboral en España}

La jornada laboral ha ido variando en todos los países industriales a lo largo del último siglo al mismo tiempo que se reajustaba el tiempo de trabajo ante los cambios técnicos y los ciclos económicos desde las últimas décadas. El tiempo de trabajo está disminuyendo en los países de la Unión Europea (OIT, 2011) y va aumentando, de forma progresiva, el número de trabajadores con una jornada inferior a la jornada estandarizada de cuarenta horas semanales distribuidas de lunes a viernes y jornada partida. La reducción del tiempo de trabajo es una forma de flexibilización muy extendida en los países industriales que está siendo una práctica común en Europa ante la última crisis económica, donde se opta por reducir la jornada laboral en vez de suprimir a una parte de la plantilla de la empresa.

Igualmente, la diversidad del tiempo de trabajo de las economías está configurando una distribución de las horas de trabajo con jornadas inferiores o superiores a la jornada estándar de cuarenta horas. La Fundación Europea (2010) estima que los trabajadores en Europa con jornadas reducidas, jornadas semanales de menos de 20 horas, han aumentado del 8\% del ańo de1991 al 14\% en 2010.

Mientras suceden estos cambios se asiste a la transformación del patrón productivo tradicional hacia un modelo con una estructura más flexible en términos funcionales, lo que ha dado lugar a un modelo de organización del trabajo basado en (Aragón, Cruces, Martínez y Rocha, 2012 p. 22): la reducción del tiempo de trabajo, la diversidad de la duración de la jornada, la variedad en la ordenación del tiempo de trabajo, una mayor flexibilidad laboral, la desincronización de los tiempos de trabajo y los tiempos vitales y la segmentación de los trabajadores por tipo de empleo y jornada laboral.

La tendencia general de reducción del tiempo de trabajo en los países europeos, también se ha dado en España con ligeras diferencias. En los años previos a la actual crisis económica, la jornada laboral media en España se hallaba por encima de la media de la UE-15; así en el ańo 2007 se registra una jornada laboral semanal de 38,4 horas frente a las 37,0 de los países de la Eurozona-17 (Eurostat, 2014).

Los datos publicados del año 2012 y elaborados por Eurostat, en cuanto al concepto de horas medias semanales trabajadas en el trabajo principal en la UE, 
oscilan entre 37,3 y 36,8; dependiendo si los datos corresponden a los países de la UE-27 o a la zona Euro-17. Espańa sigue estando por encima de la media europea con una jornada semanal de 38,1 horas en 2012, ligeramente inferior a los datos observados anteriores a la crisis; siendo Grecia uno de los países con la jornada media más larga en 42,0 horas por semana.

En el año 2012, en Reino Unido y Grecia los empleados a tiempo completo tuvieron las jornadas semanales más largas (42,8 y 43,8 respectivamente); para la UE (27) y la zona Euro (17) fueron de 41,6 y 41,5 horas respectivamente, mientras España se sitúa en este caso en la media de la UE con 41,7 horas. Las horas semanales habituales trabajadas por los asalariados a tiempo parcial ascienden a 19,9 de media en la UE en 2012. Los países que presentan los tiempos parciales más altos son Suecia y Bélgica $(23,8$ y 23,9$)$, seguido de Francia $(23,0)$; mientras que la jornada laboral a tiempo parcial con resultados más bajos la ostenta Portugal $(16,4)$, Alemania $(18,2)$, Dinamarca $(18,4)$ y España $(18,5)$.

En España con 41,8 horas semanales para los trabajadores a tiempo completo, se acerca a la media de la UE; mientras que Grecia $(44,0)$ sigue teniendo una de las jornadas más largas. Las estadísticas del tiempo parcial semanal suelen estar en la media de 20,0 horas semanales, estando España por debajo en 18,9.

En cuanto a la distribución de la población ocupada por horas en España, se ha generado un aumento del número de ocupados con jornadas reducidas (menos de 30 horas) desde el año 2001 (13,7 por ciento de los ocupados) al año 2011 , situándose en 17,6 por ciento de la población ocupada. Este crecimiento se origina al mismo tiempo que se introducen cambios en la normativa nacional sobre el trabajo a tiempo parcial, la cual ha seguido la tendencia general de flexibilización del tiempo de trabajo (Aragón et al., 2012) y, de forma más directa, con la asunción de las recomendaciones de la Unión Europea en materia de políticas de empleo, promoviendo prácticas fundamentalmente cuantitativas (González y Guillén, 2009).

La cuestión de la flexibilidad de la distribución del tiempo de trabajo está configurando jornadas de trabajo no-estandarizadas o consideradas atípicas, por extenderse a franjas horarias y días de la semana tradicionalmente ociosos para una gran parte de trabajadores como sábados, domingos y horarios nocturnos. Es decir, cualquier espacio de tiempo semanal puede convertirse en horario laborable (Prieto, 2008), o por extensión cualquier hora del año, derivando en la anualización de las horas de trabajo. Como expresa Sirvent (2009), la mayor diversidad en los tiempos de trabajo nos está llevando a configurar horarios y jornadas no-estándares en horarios poco sociales. En este sentido, la desincronización de los tiempos de trabajo están ligados a los grandes cambios familiares, sociales y económicos (Durán, 2002) como la incorporación de la mujer al mercado laboral, el descenso de la natalidad o las transformaciones del estilo de vida en cuanto a la relación de tiempos entre consumo y ocio. En definitiva, las for- 
mas de segmentación laboral, como la relación entre trabajo a tiempo parcial y la dualización de los mercados de trabajo, están configurando categorías de trabajadores con heterogéneas condiciones en el mercado de trabajo.

En cualquier caso, la mayor parte de los trabajadores siguen teniendo jornadas consideradas típicas o estándar frente a un número reducido de trabajadores con jornadas y horarios atípicos; hay que reconsiderar cuál será la tendencia en cuanto a jornadas de trabajo o clases de trabajadores en el mundo ante la creciente diversidad. En este ámbito, sería adecuado reflexionar sobre el interés mostrado por trabajadores y empresarios sobre las propuestas de flexibilización del tiempo de trabajo, con el objeto de plantear prácticas flexibilizadoras coherentes y con el mayor consenso posible.

La normativa en España sigue las directrices internacionales y regula la jornada legal máxima en cuarenta horas semanales de trabajo efectivo en promedio de cómputo anual. La duración de la jornada será pactada ${ }^{2}$ en convenio colectivo o contrato de trabajo ${ }^{3}$. La jornada habitual de trabajo es la jornada corriente o usual de trabajo que equivale a la suma de la jornada pactada y las horas extraordinarias efectuadas habitualmente.

Entre las diferentes estadísticas en España que registran la jornada laboral ${ }^{4}$, la Encuesta de Población Activa (EPA) es la única que estima la jornada habitual de trabajo semanal. Los resultados de las diversas encuestas sobre la jornada laboral no son coincidentes debido a las distintas fuentes de información (Pérez, 2006; Aragón et al. 2012). Así, la Encuesta Trimestral de Costes Laborales (ETCL) y la Encuesta de Coyuntura Laboral (ECL) registran los datos de empleo desde el punto de vista del empresario, mientras que la EPA realiza su cálculos desde el punto de vista del trabajador. Otra estadística de referencia para el cálculo de la jornada de trabajo es la Estadística de Convenios Colectivos, a partir de la cual la información que obtiene se fundamenta en los datos de las Comisiones Negociadoras de los Convenios Colectivos.

Los resultados sobre el número de horas trabajadas al año es muy dispar según la estadística consultada (tabla 2); la EPA es la que registra el mayor número horas trabajadas al año y plantea cifras superiores a las otras encuestas: la jornada

${ }^{2}$ La OIT establece diferentes conceptos en relación a la jornada de trabajo, así clasifica las horas trabajadas en jornada pactada, jornada habitual, jornada efectivamente trabajada y jornada trabajada.

${ }^{3}$ La normativa que se puede consultar a este respecto es la siguiente: R.D. 2001/83, arts. 45, 46 y 47; Ley 24/92; Ley 25/92; Ley 26/92; R.D.L.G. 1/95, arts. 34 a 38; R.D. 1561/95; Ley 9/10.

${ }^{4}$ Estadística de Convenios Colectivo de Trabajo, proporciona información sobre la jornada pactada anual. La Encuesta Trimestral de Costes Laborales (ETCL) considera las horas efectivamente trabajadas por el trabajador (son las horas pactadas y las horas extraordinarias) de forma mensual. La Encuesta de Coyuntura Laboral (ECL) estima la jornada efectivamente trabajada y su cálculo se refiere al trimestre. La Encuesta de Población Activa, estima varias jornadas laborales: jornada pactada, horas efectivamente trabajadas y la jornada habitual de trabajo, y el período considerado es la semana. 
laboral habitual anual calculada por la EPA en el año 2012, fue de 1.739,9 horas que suponen una jornada semanal de 38,9 (las horas efectivamente trabajadas ascienden a $1.671,4)$ muy superior a las $1.563,8$ de la ECL, o a las $1.597,2$ horas anuales calculada por la ETCL. La estadística de convenios colectivos alcanza 1.733,2 horas, siendo la que más se aproxima al cálculo de la EPA.

La jornada habitual de trabajo estimada por la EPA ha ido disminuyendo de forma moderada desde el año 2004 (39,6 horas semanales) hasta las 38,3 horas semanales consignadas en el año 2013.

Tabla 2

La jornada de trabajo según diferentes fuentes estadísticas

\begin{tabular}{lccccc}
\hline \multicolumn{1}{c}{ Fuentes estadísticas } & 2004 & 2008 & 2012 & 2T-2013 & Sep. 2013 \\
\hline EPA(1) & & & & & \\
J. habitual h/sem. & 39,6 & $38,9-4 \mathrm{~T}$ & $38,1-4 \mathrm{~T}$ & 37,9 & $38,3-3 \mathrm{~T}$ \\
J. habitual anual & $1.808,4$ & 1776,4 & 1739,9 & 1730,7 & 1749 \\
\hline EPA & & & & & \\
$\quad$ J. efectiva & 38,2 & $38,1-4 \mathrm{~T}$ & $36,6-4 \mathrm{~T}$ & 37,3 & 37,8 \\
J. efectiva anual & $1.744,5$ & 1739,9 & 1671,4 & 1703,3 & 1726,2 \\
\hline ETCL(2) & & $142,2-2 \mathrm{~T}$ & $133,1-2 \mathrm{~T}$ & 136 & \\
2. ${ }^{\circ}$ trimestre & $1.652,4$ & $1.706,4$ & $1.597,2$ & $1.632,0$ & Sin datos \\
\hline ECL & $1.646,2$ & 1.612 & $1.563,8$ & Sin datos & Sin datos \\
\hline Convenios colectivos & $1.758,0-$ & 1.749 & $1.733,2$ & $1.755,5$ & $1.752,8$ \\
\hline
\end{tabular}

(1) La EPA realiza el cálculo de diferentes conceptos de jornada laboral: el número medio de horas efectivamente trabajado por los ocupados que han trabajado, el número medio de horas efectivamente trabajadas por los ocupados hayan o no trabajado y el número medio de horas habitualmente trabajadas por los ocupados. En la tabla 2 se presentan los datos de la jornada efectiva para los ocupados que han trabajado y la jornada habitualmente trabajada. Para pasar de la jornada semanal calculada por la EPA a la anual, se utiliza la fórmula JA $=274 \times \mathrm{JS} / 6$. Donde JA es jornada anual y JS es jornada Semanal. Los 274 días es el resultado de la siguiente operación $274=365$ - 30 días de vacaciones -13 días festivos - 48 domingos; la división por seis corresponde a los días trabajados a la semana. Esta fórmula surge en el Acuerdo Interconfederal firmado por UGT y CEOE/CEPYME en el año 1983. A resultas de esta fórmula, Pérez (2006) propone que se ajuste la fórmula a la situación mayoritaria de los trabajadores, los cuales no trabajan los sábados, con lo cual la fórmula quedaría: $\mathrm{JA}=238 \times \mathrm{JS} / 5,25$. Además se ha indicado en la fila de la EPA las horas habituales de trabajo y efectivas por horas semanales y anuales.

(2) Las jornadas mensuales para convertirlas en anuales se multiplican por doce. En el caso de la ECTL se ha considerado el segundo trimestre de los cuatro años.

Fuente: EPA, ECTL, ECL, Convenios colectivos. 
La definición de jornada de trabajo a tiempo parcial hace referencia a una jornada habitual de trabajo que es la definición que utiliza la EPA; con lo cual, si no se tiene en cuenta el término estadístico y se recurre al concepto metodológico sin matices, una jornada semanal inferior en un minuto a la jornada habitual, sería considerada una jornada a tiempo parcial sin embargo las estadísticas no reconocen a circunstancia.

También se ha revisado los datos sobre la media de la jornada en los trabajos a tiempo parcial. Para ello, se han comparado los resultados en diversos países con características de desarrollo similares a España 5 , en general, la jornada media a tiempo parcial no es superior a las 20 horas semanales para todos los países observados.

Tabla 3

Jornada efectiva media de trabajo y horas extraordinarias en España

\begin{tabular}{cccc}
\hline Años & $\begin{array}{c}\text { Trabajadores } \\
\text { tiempo completo }\end{array}$ & $\begin{array}{c}\text { Trabajadores } \\
\text { a tiempo parcial }\end{array}$ & $\begin{array}{c}\text { \% tiempo parcial } \\
\text { sobre t. completo }\end{array}$ \\
\hline 1991 & $1.741,4$ & 887,4 & 50,9 \\
1992 & $1.739,7$ & 897,6 & 51,6 \\
1993 & $1.734,4$ & 904,8 & 52,2 \\
1994 & $1.735,4$ & 925,2 & 53,3 \\
1995 & $1.750,3$ & 934,1 & 53,4 \\
1996 & $1.761,6$ & 927,9 & 52,7 \\
1997 & $1.767,8$ & 942,0 & 53,3 \\
1998 & $1.770,1$ & 987,4 & 55,8 \\
1999 & $1.772,5$ & 997,0 & 56,2 \\
2000 & $1.775,3$ & 978,1 & 55,1 \\
2001 & $1.768,5$ & $1.008,4$ & 57,0 \\
2002 & $1.767,6$ & $1.026,4$ & 58,1 \\
2003 & $1.758,5$ & $1.023,9$ & 58,2 \\
2004 & $1.755,2$ & $1.023,9$ & 58,3 \\
2005 & $1.749,4$ & $1.030,7$ & 58,9 \\
2006 & $1.740,4$ & $1.019,9$ & 58,6 \\
2007 & $1.734,4$ & $1.024,8$ & 59,1
\end{tabular}

${ }^{5}$ La OIT define la jornada efectiva de trabajo como la jornada efectivamente trabajada en un período de referencia, en este caso un año, englobando las horas normales de trabajo y las horas extraordinarias; además debe incluir las horas dedicadas en el lugar de trabajo a la conservación, reparación y limpieza de maquinarias y herramientas, el tiempo trascurrido por la espera de trabajo, el paro, averías o accidentes de la maquinaría y los descansos reglamentarios (Pérez, 2006). 


\begin{tabular}{cccc}
\hline Años & $\begin{array}{c}\text { Trabajadores } \\
\text { tiempo completo }\end{array}$ & $\begin{array}{c}\text { Trabajadores } \\
\text { a tiempo parcial }\end{array}$ & $\begin{array}{c}\text { \% tiempo parcial } \\
\text { sobre t. completo }\end{array}$ \\
\hline 2008 & $1.730,5$ & $1.029,8$ & 59,5 \\
2009 & $1.715,1$ & $1.019,5$ & 59,4 \\
2010 & $1.717,3$ & $1.028,2$ & 59,9 \\
2011 & $1.715,1$ & $1.038,4$ & 60,5 \\
2012 & $1.712,8$ & $1.036,6$ & 60,5 \\
\hline
\end{tabular}

Fuente: Encuesta de Coyuntura Laboral ${ }^{6}$, Ministerio de Empleo y Seguridad social, 2012.

A su vez, las estadísticas sobre el tiempo medio de trabajo parcial en Espańa (tabla 3) reflejan una media de tiempo en torno a las 21 horas desde 1991 hasta el ańo 1998; a partir de esa fecha aumenta la media de horas a tiempo parcial semanales llegando a suponer hasta el 60,5 por ciento de la jornada semanal (24,2 horas semanales) en el año 2011. La serie de datos desde 1999 a 2012 pertenece a la jornada efectiva media y las horas extraordinarias de los sectores industrial, construcción y servicios, no estando incluido el sector agrícola. El resultado en toda la serie (tabla 3) presenta una gran diferencia en el tiempo de trabajo: los trabajadores a tiempo parcial han trabajado la mitad de las horas que un trabajador a tiempo completo, aumentando el número de horas a lo largo de todo el período.

Con lo cual, un trabajo a tiempo parcial igual o inferior a 30 horas semanales, tal y como es contemplado en otros países, sería un límite razonable para su determinación. En general, las jornadas laborales a tiempo parcial suelen estar por debajo de la frontera de las 30 horas semanales. De esta manera, desaparece la arbitrariedad del concepto y la consideración subjetiva que utiliza la estadística.

Por otro lado, las estadísticas internacionales podrían ser comparables y se podrían realizar investigaciones con un criterio común y no teniendo que decidir cuál es el punto de corte para elaborar las encuestas y las estadísticas.

El establecimiento de un límite cuantitativo puede restar flexibilidad a este tipo de contrato, sin embargo, una delimitación coherente ofrece posibilidades de entender mejor la realidad de las nuevas condiciones laborales y proponer soluciones prácticas para este tipo de trabajo.

${ }^{6}$ La información proviene de la Encuesta de Coyuntura Laboral (ECL) que elabora trimestralmente la Subdirección General de Estadística del Ministerio de Empleo y Seguridad social. Esta encuesta se implantó en el segundo trimestre de 1990, modificándose su metodología en el primer trimestre de 1997. Los datos de la Encuesta de Coyuntura Laboral no están actualizados a partir del cuarto trimestre de 2012, ya que esta Encuesta ha dejado de realizarse. 


\subsection{La normativa de los contratos a tiempo parcial}

Una vez revisado el concepto y la delimitación del tiempo para los trabajos a tiempo parcial, en este apartado se describe, de forma concisa, la normativa desarrollada atribuible a este tipo de contrato.

Hasta el Estatuto de los Trabajadores aprobado y publicado en el año 1980, los contratos a tiempo parcial no tenían regulación en Espańa; no obstante, a partir de su inclusión en el año 1980, la normativa limita la celebración de los contratos a tiempo parcial a determinadas categorías de trabajadores. Con la reforma del Estatuto de los Trabajadores en el año 1984, se amplía la regulación del contrato a tiempo parcial, extendiéndose su uso a todos los trabajadores cuya jornada de trabajo sea inferior a dos tercios de una jornada de trabajo habitual, celebrándose para todo tipo de modalidades contractuales. Además, aparece el contrato de relevo y se regula la jubilación parcial como nueva modalidad contractual en el año 1984; de tal manera que los trabajadores que cumplan los requisitos para tener derecho a la jubilación, excepto el de la edad, pueden acogerse a una reducción horaria de su contrato de trabajo en un 50 por ciento de la jornada habitual y transformarlo en un contrato a tiempo parcial hasta la edad de jubilación.

La utilización de la contratación a tiempo parcial en España desde su regulación ha sido muy reducida puesto que las restricciones normativas no han fomentado el uso por parte de las empresas. Ante esta situación, el desarrollo de la normativa ha tratado de fomentar y flexibilizar el contrato a tiempo parcial, sin embargo, no se ha logrado alcanzar las tasas de contratos a tiempo parcial de países de nuestro entorno.

En los cambios normativos de la contratación a tiempo parcial formalizados desde el año 1984 hasta la actualidad se ha regulado diversos aspectos. A continuación se exponen los principales.

En primer lugar, destaca la arbitrariedad a la hora de definir y reconocer 'un trabajo a tiempo parcial'. La norma, a veces, ha sido precisa estableciendo un porcentaje sobre la jornada habitual de trabajo a tiempo completo; otras veces la regla no ha concretado ni porcentaje ni cuantía sobre la jornada habitual de trabajo para establecer y distinguir al trabajo a tiempo parcial, únicamente indicando que sea inferior a la jornada habitual de trabajo.

Un segundo aspecto voluble con cada nueva norma han sido las variaciones en el número de años previos a la edad de jubilación que da derecho a la pensión de jubilación $y$, por tanto, a la transformación de los contratos a tiempo completo por contratos a tiempo parcial. En el año 1984, podían acogerse a este sistema aquellos trabajadores que les faltaban tres años para alcanzar la edad de jubilación o que tenían sesenta y dos ańos. En la reforma del ańo 2007, para 
acceder a la modalidad de jubilación parcial se supedita el acceso a la misma, como regla general, al cumplimiento de 61 ańos de edad, a que el trabajador tenga una antigüedad de 6 años en la empresa y a que acredite un período de cotización de 30 años.

En relación a la jubilación parcial, se ha puesto de manifiesto los numerosos cambios para decretar la disminución de la jornada habitual de trabajo y poder considerar la jornada a tiempo parcial. En esta cuestión la normativa también ha ido cambiando, estableciendo una cuantía porcentual sobre la jornada habitual de trabajo en algunas reformas, o bien la norma ha optado por establecer un mínimo y un máximo de la jornada habitual para calcular la jornada a tiempo parcial. En el año 1980, la jornada a tiempo parcial de un trabajador parcialmente jubilado se reducía hasta el 50 por ciento de su jornada. La Ley 40/2007 dispone unos límites para acogerse a la jubilación parcial, que son la reducción de la jornada de trabajo entre un $25 \%$ y un $75-85 \%$, considerada normal u ordinaria para ese tipo de trabajo.

En cuanto a las prestaciones intrínsecas en los contratos a tiempo parcial como la cobertura de prestaciones sociales, la atención sanitaria, el seguro de desempleo y la prestación por jubilación, se han ido modificando para hacer más atractiva esta forma contractual a trabajadores. En el punto 3 del artículo 12 del RDLeg $1 / 1995$, de 24 de marzo de $1995^{7}$, se fija el límite para tener derecho a las prestaciones sociales, de tal manera que aquellos contratos a tiempo parcial con un número de horas inferiores a 12 a la semana o 48 días al mes ${ }^{8}$ (Pedrajas, 1994; Segura, 2001), sólo tienen derecho a las prestaciones sanitarias por accidentes de trabajo y enfermedades profesionales, por contingencias comunes y la prestación económica correspondiente a los períodos de descanso por maternidad y Fondo de Garantía Salarial, excluyéndose, entre otras, las prestaciones por desempleo. Con la reforma de 1997 se incluyen en las cotizaciones todas las contingencias para los denominados contratos de duración marginal (12 horas semanales o 48 horas mensuales). En la actualidad, la protección social de los trabajadores contratados a tiempo parcial abarca la totalidad de situaciones y contingencias previstos en el Régimen de la Seguridad Social en el que estén encuadrados, de acuerdo con las reglas para el cálculo de la adquisición de las prestaciones.

Otra de las características de los contratos a tiempo parcial es saber si la norma establece o no horas extraordinarias. La normativa desarrollada en

\footnotetext{
7 Texto refundido de la ley del Estatuto de los Trabajadores, BOE 29 de marzo 1995, núm. 75/1995.

${ }^{8}$ Dentro, de la contratación a tiempo parcial, se consideran los contratos de duración marginal a aquellos cuya jornada es inferior a las 12 horas semanales o 48 horas mensuales (Segura 2001, p. 174). Estos contratos de duración marginal tienen una protección social limitada en cuanto a la atención sanitaria, seguro de desempleo y prestación por jubilación.
} 
los años noventa y en la primera década de este siglo es tajante a la hora de clarificar este concepto; expresando que los contratos a tiempo parcial por tiempo indefinido pueden tener horas complementarias (pagadas igual que una hora ordinaria) con los requisitos específicos, pero no pueden tener horas extraordinarias (Goerlich, 2008). La normativa del año 2011 (Orden TIN/41/2011) establece que, por motivos de fuerza mayor, una empresa puede establecer horas extraordinarias para los contratos a tiempo parcial. Pero será en el Real Decreto-Ley 3/2012 donde se admita la celebración de horas extraordinarias para los contratos a tiempo parcial ${ }^{9}$, y su inclusión en la base de cotización por contingencias comunes. De esta manera, conviven las horas ordinarias, las complementarias y las extraordinarias. La suma de todas ellas no debe exceder el límite legal del tiempo de trabajo para los contratos a tiempo parcial.

Esta variedad de horas y su cómputo económico, sin límites cuantitativos específicos, no han ayudado a precisar los conceptos asociados al contrato a tiempo parcial; por el contrario, es difícil averiguar qué horas de trabajo (ordinarias, complementarias y /o extraordinarias) son las computables a efectos de bases de cotización a la Seguridad Social y para el cálculo de las bases reguladoras de las prestaciones. Sin embargo, la última normativa correspondiente al Real Decreto Ley 16/2013 publicado en el Boletín Oficial del Estado el 22 de diciembre de 2013, ha eliminado las horas extraordinarias en la contratación a tiempo parcial, a excepción de lo establecido en el artículo 35.3 del Estatuto de los Trabajadores.

Finalmente, el menor uso del contrato a tiempo parcial en Espańa respecto a los países de su entorno, puede deberse a la imprecisa y mutable normativa, sin embargo, la creación de empleo desde el año 2009, se ha centrado en la contratación a tiempo parcial de forma más intensa que en períodos anteriores. Con lo cual, es necesario reflexionar sobre las causas que llevan a la utilización de este contrato en el actual período recesivo, es posible que se hallen en aspectos relacionados con los ciclos económicos y con elementos institucionales. El alcance de las mutaciones de la norma y arbitrariedad del concepto son elementos secundarios en la utilización de esta contratación por parte de las empresas.

9 Real Decreto-Ley 3/2012; capítulo II, artículo 5; modifica la letra c) del apartado 4 del artículo 12 del Texto Refundido de la Ley del Estatuto de los Trabajadores, aprobado por Real Decreto Legislativo 1/1995, de 24 de marzo. 


\section{El empleo creado mediante el emprendimiento social en Andalucía. Un análisis comparativo del trabajo a tiempo parcial}

El empleo a tiempo parcial en España se ha extendido en los últimos años de crisis económica, sin embargo, la mayoría de los encuestados con un contrato a tiempo parcial afirman tener este tipo de empleo porque no han encontrado un empleo a tiempo completo, con la merma de ingresos que conlleva y las precarias condiciones de vida que las mínimas rentas aportan. En el año 2013, el 60,4\% de hombres y el 69,1\% de mujeres alegan esta razón (INE, 2014).

Una de las alternativas planteadas a nivel institucional, ante la escasez de $\mathrm{em}$ pleo asalariado, ha sido la promoción de las EES. En la Comunidad Autónoma Andaluza (CAA), las EES y los empleos creados por ellas tienen una gran importancia en términos comparativos con otras CC.AA. Por este motivo, en este epígrafe se desarrolla, la evolución de las EES y del empleo en Andalucía y en el resto de CC. AA., clasificando el empleo a tiempo parcial creado.

En primer lugar, se observa la evolución de los empleos creados en Andalucía por las empresas de emprendimiento social y los contrastamos con los obtenidos en otras Comunidades Autónomas (CC.AA.) con los datos de empleo total a nivel nacional.

Gráfico 1

Evolución del número de EES por CC.AA. en porcentaje sobre el total

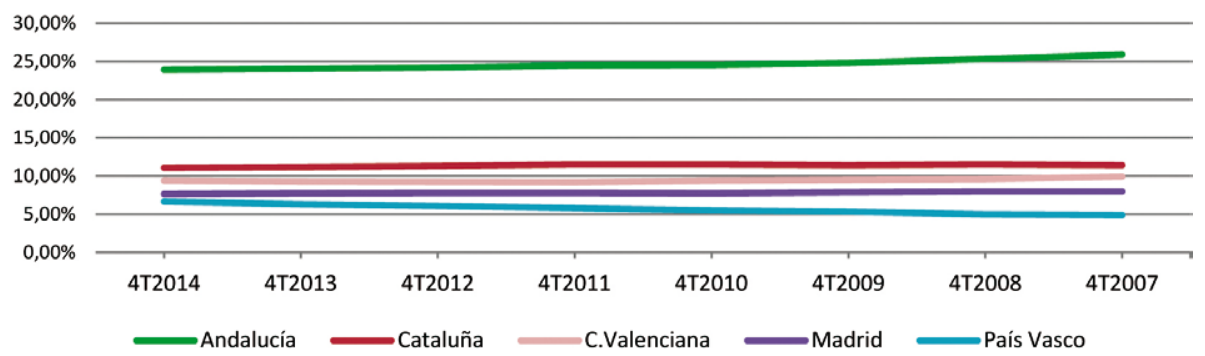

Fuente: CEPES-Andalucía, 2015. 
Gráfico 2

Evolución del empleo en EES por CC.AA. en porcentaje sobre el total

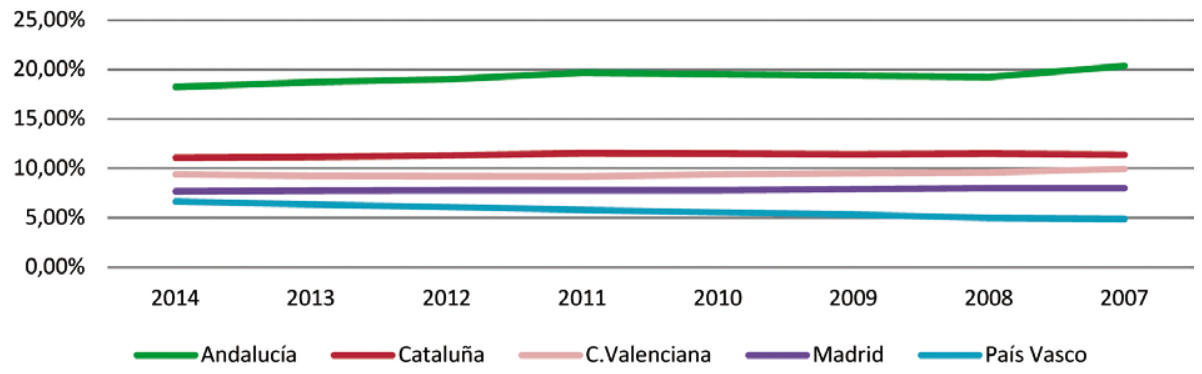

Fuente: CEPES-Andalucía, 2015.

Las EES predominan en Andalucía, Cataluña, Comunidad Valenciana, Madrid y País Vasco (gráficos 1 y 2). Siendo la CAA, la región con mayor número de EES implantadas respecto al resto de comunidades, representando el 26-24\% del total nacional y el 20,3-18\% del empleo. A gran distancia de Andalucía se encuentra Cataluña con el 11,08\% de empresas y la Comunidad Valenciana con 9,38\% (datos de 2014); el cuarto y quinto lugar lo ocupan Madrid y el País Vasco con el 7,65\% y el 6,64 respectivamente. En todas las CC.AA. se ha producido un descenso del número de empresas en el período observado, muy significativo en el caso de Andalucía donde han desaparecido un 38,7\% de las empresas registradas en el ańo 2007.

De la misma forma ha sucedido con el empleo del sector, de los 442.326 empleos registrados en 2007, se han perdido 83.396 empleos en el total nacional durante los ańos de crisis económica hasta 2014. Sin embargo, la reducción de empleo no se ha distribuido de forma equitativa por CC.AA.; mientras en Andalucía se ha perdido el 38\% del empleo en el período, en el País Vasco la pérdida se reduce al 11,36\%. Si bien, el descenso ha sido generalizado, el empleo en Navarra y Cataluña se ha mantenido y en Ceuta ha aumentado, presentado así una excepción en esta ciudad autónoma. Con todo, es el País Vasco, la región con mayor número de empleos en el sector después de Andalucía $(15,71 \%)$, seguida de la Comunidad Valenciana y Cataluña (14,6\% y $12,03 \%$ respectivamente).

En cuanto a la fórmula jurídica más utilizada según las sociedades registradas en la Seguridad Social en el período analizado, sigue siendo la creación de cooperativas las que alcanzan el mayor volumen de registros. Las sociedades anónimas y limitadas se han reducido, de forma drástica, aproximadamente a la mitad en el ańo 2014 respecto a las registradas en el ańo 2007, tanto a nivel nacional y regional, en concreto el $44,7 \%$ de sociedades limitadas y el 48,7 
de sociedades anónimas. La disminución ha sido mucho menor en el caso de las cooperativas, en el cómputo nacional, el descenso ha sido de 21,2\%, y en Andalucía algo superior, con una reducción del 29,3\% de cooperativas.

El análisis del empleo en el período según fórmula jurídica sigue las pautas de destrucción de empresas pero de forma más acentuada. La mayor destrucción de empleo se ha producido en las Sociedades Limitadas Laborables y Anónimas Laborales, en éstas últimas la ocupación ha descendido de forma drástica un $56,2 \%$ en el total de Espańa, siendo un descenso muy acusado en Andalucía, llegando a alcanzar el $69.4 \%$. El empleo se ha mantenido gracias a la moderada destrucción de empleo de las cooperativas (el $11 \%$ en España y 13,6\% en Andalucía), con un descenso relativamente bajo si comparamos con otros tipos de sociedades.

La destrucción de la ocupación en todos los sectores y actividades del sistema económico español, se ha transmitido también a la esfera de la economía social (gráfico 3). El empleo disminuye durante todo el período observado en paralelo al aumento del empleo a tiempo parcial (gráficos 4 y 5). Si bien, en el conjunto de España llega a alcanzar el 15,7\%, la creación del empleo en Andalucía ha arrojado unos resultados superiores al $20 \%$ de la ocupación a tiempo parcial en las EES, manteniéndose este porcentaje en 2013 y 2014 al igual que la media de EES del resto del país.

Gráfico 3

\section{Evolución del Empleo en EES}

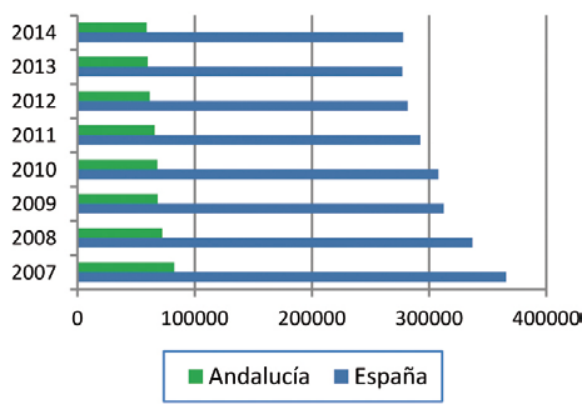

Fuente: CEPES-Andalucía.

\section{Gráfico 4}

Ocupados en España a tiempo parcial

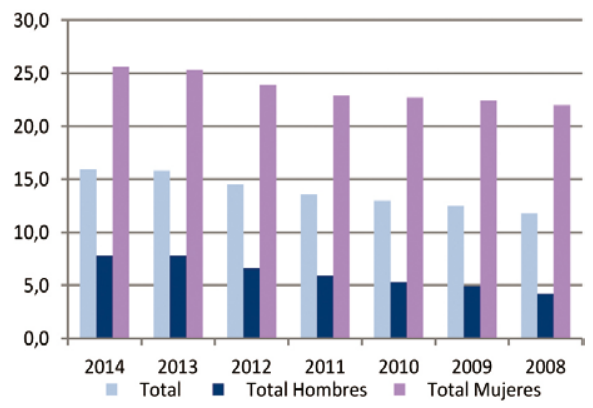

Fuente: INE, EPA. 


\section{Gráfico 5}

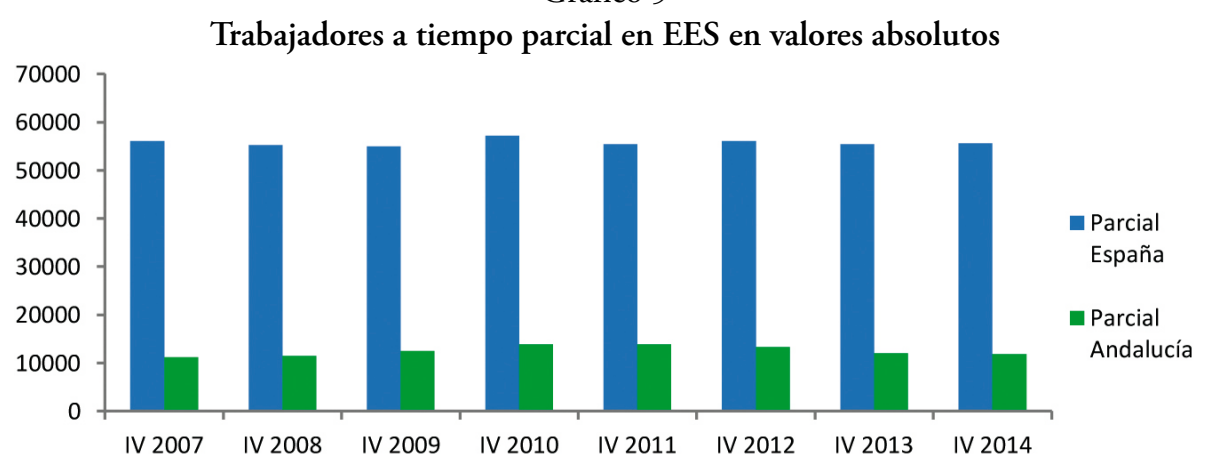

Fuente: CEPES-Andalucía.

En los gráficos 6, 7 y 8 se observa la evolución de los trabajadores a tiempo parcial en España y Andalucía. En el resto de España la ocupación a tiempo parcial ha fluctuado en todo el período, durante los dos primeros años del período observado desciende para alcanzar el máximo de empleo en el año 2009, aunque volvió a descender en los años siguientes, se observa un nuevo repunte en 2012. A partir de este último año ha disminuido o se ha mantenido relativamente estable el número de personas empleadas a tiempo parcial en las EES en España (sobre los 55.000 empleos).

\section{Gráfico 6}

Trabajadores a tiempo parcial en EES. Porcentaje sobre el total de empleo en EES

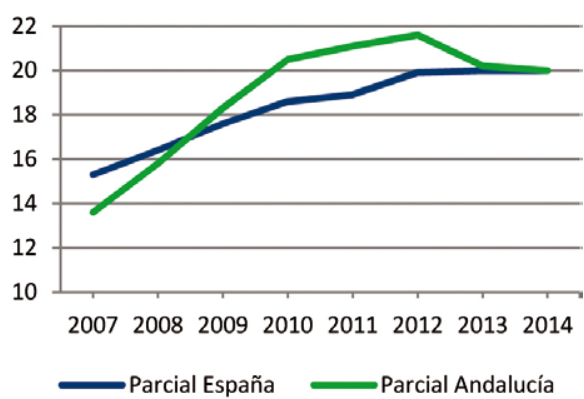

Fuente: CEPES-Andalucía.

\section{Gráfico 7}

Trabajadores a tiempo parcial en EES.

En España

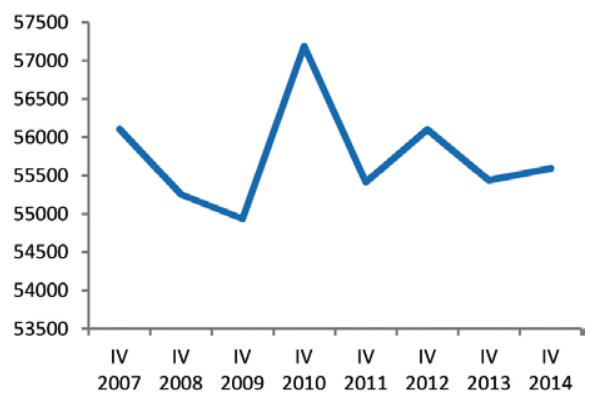

Fuente: CEPES-Andalucía.

En cuanto a la evolución del tiempo parcial en Andalucía, tras una subida más intensa y continuada desde 2007 a 2010, se produce una caída que se ha ido moderando a partir del año 2012. Esta evolución no ha ido en paralelo al descenso de empresas en el sector (gráfico 9), cuya caída ha sido continuada 
desde el año 2008. En el año 2014 el empleo a tiempo parcial en España y Andalucía constituye el $20 \%$ del empleo del sector.

\section{Gráfico 8}

Trabajadores a tiempo parcial en EES.

En Andalucía

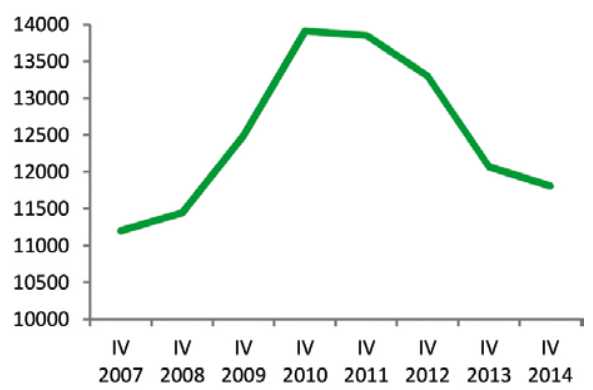

Fuente: CEPES-Andalucía.
Gráfico 9

EES de nueva creación.

En Andalucía

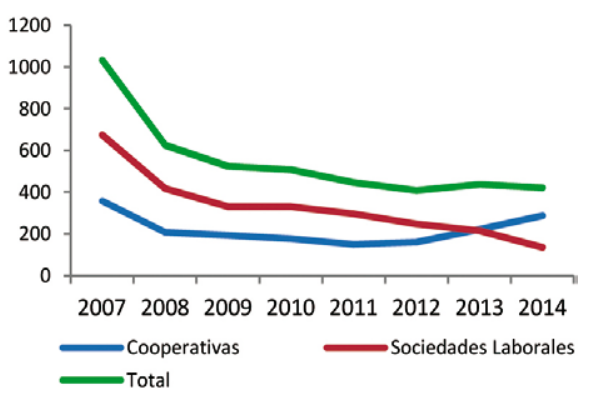

Fuente: CEPES-Andalucía.

Es decir, estamos ante un fenómeno atípico dentro de un contexto económico recesivo, el empleo creado durante la crisis económica es un empleo a tiempo parcial en una mayor proporción que en períodos recesivos anteriores. Este fenómeno también se ha contagiado a las EES en Andalucía.

En relación a la evolución del empleo en las EES, distinguiendo el empleo indefinido y temporal (gráficos 10 y 11), de forma similar al resto de empresas, la destrucción de empleo temporal ha sido la nota común para todas las empresas; en cuanto al empleo indefinido, tras una caída vertiginosa en los primeros años, se ha frenado el descenso desde 2012.

Gráfico 10

Trabajadores indefinidos en EES.

En Andalucía

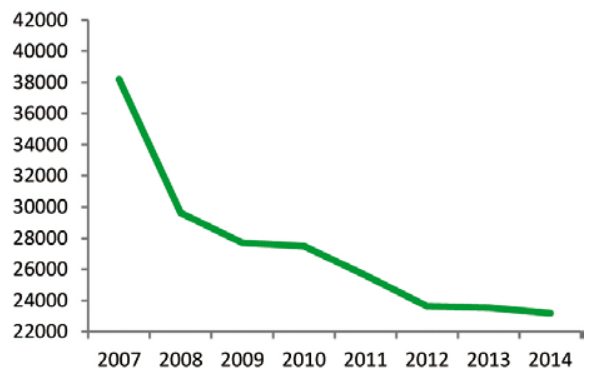

Fuente: CEPES-Andalucía.
Gráfico 11

Trabajadores temporales en EES. En Andalucía

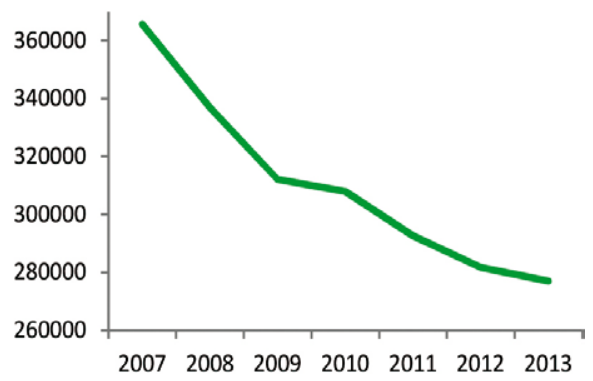

Fuente: CEPES-Andalucía. 
Hay un aspecto del empleo a tiempo parcial y es la feminización de este tipo de trabajo, los estudios e investigaciones apuntan a que, en mayor medida, las mujeres soportan las mayores tasas de ocupación a tiempo parcial.

Las estadísticas elaboradas por CEPES no reflejan la distinción entre trabajadoras a tiempo completo y parcial, no obstante hacemos una breve referencia a la evolución del empleo por sexo. En general, tanto en Espańa como en Andalucía (gráficos 14 y 15), el descenso del empleo en las EES en los hombres ha seguido la misma tendencia, se ha paralizado la caída en 2012 tanto en Andalucía como en España, donde ha comenzado a aumentar el empleo de los varones en las EES.

Gráfico 12

Trabajadores-Mujeres en EES. En España

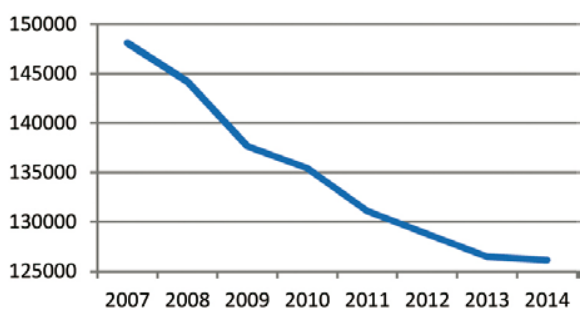

Fuente: CEPES-Andalucía.

Gráfico 14

Trabajadores-Hombres en EES.

En España

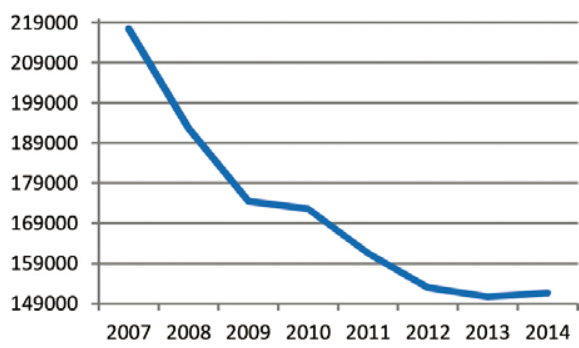

Fuente: CEPES-Andalucía.
Gráfico 13

Trabajadores-Mujeres en EES.

En Andalucía

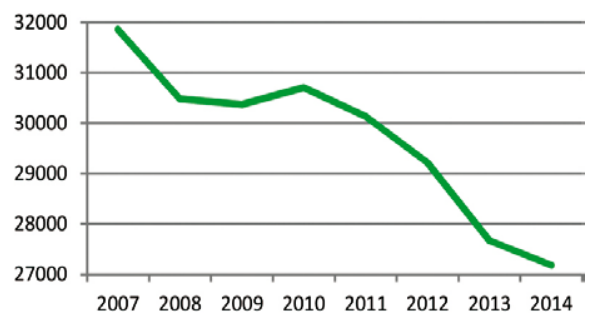

Fuente: CEPES-Andalucía.

Gráfico 15

Trabajadores-Hombres en EES.

En Andalucía

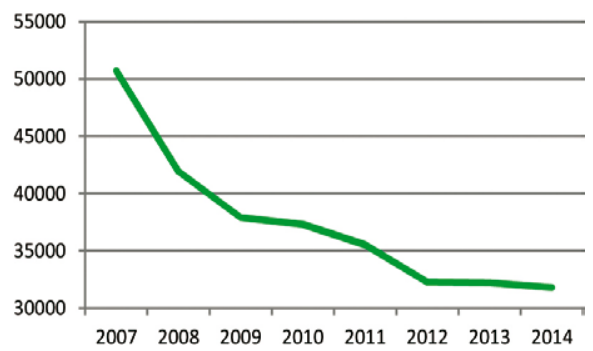

Fuente: CEPES-Andalucía. 
Sin embargo, la pauta seguida por el empleo femenino a nivel nacional no coincide con la trayectoria andaluza. Mientras que la tendencia general ha sido de descenso (gráficos 12 y 13), de forma similar a los varones. En Andalucía se mantuvo el empleo femenino en las EES en 2009 con un ligero aumento en el año 2010. A partir de este año se inicia un descenso muy acusado coincidiendo con la tendencia nacional y de varones.

\section{Reflexiones finales}

De los elementos determinantes de un empleo de calidad, en este trabajo se ha analizado la jornada de trabajo, en concreto, el empleo a tiempo parcial. En los últimos años, el empleo a tiempo parcial ha tenido gran relevancia en la creación de empleo en España a diferencia de otros períodos recesivos. En este escenario, se ha observado el empleo a tiempo parcial creado por las EES en Andalucía, para establecer si se producía el mismo patrón de empleo que en el resto de Comunidades Autónomas.

Una de las apreciaciones de este trabajo reside en la conveniencia de establecer una frontera para la consideración del trabajo a tiempo parcial en 30 horas semanales, tal y como es contemplado en algunos países. En general, las jornadas laborales a tiempo parcial suelen estar por debajo de la frontera de las 30 horas semanales. De esta manera, desaparece la arbitrariedad del concepto y la consideración subjetiva que utiliza la estadística. Además, las estadísticas internacionales podrían ser comparables y se podrían realizar investigaciones con un criterio común y no teniendo que decidir cuál es el punto de corte considerado para elaborar las encuestas.

El establecimiento de un límite cuantitativo puede restar flexibilidad a este tipo de contrato, sin embargo, una delimitación coherente ofrece posibilidades de entender mejor la realidad de las nuevas condiciones laborales y proponer soluciones prácticas para este tipo de trabajo.

La volubilidad de la normativa complica la utilización por parte de las empresas del transmutado contrato a tiempo parcial. Sin embargo, a pesar de todos los cambios, en el período de crisis actual, ha sido uno de los contratos más utilizados por parte de las empresas espańolas, con lo cual podemos preguntarnos si estamos transitando del modelo de temporalidad al modelo de reducción de jornada mediante la extensión de la contratación a tiempo parcial.

En cuanto a las conclusiones del empleo generado por las EES, se ha inferido que más del $25 \%$ de las de EES y del $20 \%$ del empleo se encuentra en territorio andaluz. En el período observado desde 2007 a 2014, la reducción del 
número de empresas y empleo ha sido más acusada en Andalucía que en otras CC.AA. (en Andalucía se ha perdido el $38 \%$ del empleo del sector mientras que en el País Vasco ha sido el 11,36\%).

El empleo a tiempo parcial ha aumentado, de forma comparativa con los ocupados a jornada completa, durante todo el período observado en España y en Andalucía, estabilizándose o disminuyendo ligeramente desde el año 2012. Con todo, al observar el número de ocupados a tiempo parcial en las EES, a nivel estatal ha habido oscilaciones durante todo el período aumentando a partir del ańo 2012, sin embargo, en Andalucía ha habido menos oscilaciones, creciendo hasta el año 2009, y en descenso desde esa fecha. En el año $2014 \mathrm{el} \mathrm{em-}$ pleo a tiempo parcial en las EES en España y en Andalucía constituye el 20\% del empleo del sector.

La situación del mayor empleo femenino en las EES en Andalucía, invita a reflexionar sobre el grado de feminización del empleo a tiempo parcial creado, ya que las fuentes consultadas no muestran distinción de la jornada laboral por sexo, si bien es la tendencia en el resto de actividades económicas. Es posible que el aumento del trabajo a tiempo parcial en Andalucía en las EES esté relacionado con el crecimiento del empleo de la ocupación femenina.

Es decir, estamos ante un fenómeno atípico dentro de un contexto económico recesivo, el empleo creado durante la crisis económica es un empleo a tiempo parcial en una mayor proporción que en períodos recesivos anteriores. Este fenómeno también se ha transmitido a las EES en Andalucía.

Uno de los argumentos más extendidos para promocionar el trabajo a tiempo parcial en los últimos ańos, ha consistido en tratar de incorporar flexibilidad laboral a los rígidos mercados de trabajo europeos. Sin embargo, el trabajo a tiempo parcial ha sido considerado como una estrategia política de los países y las áreas económicas más que una forma deseable de flexibilidad seleccionada por los trabajadores (Tonrs, 2005). Los planteamientos desde la UE, nos llevan a reflexionar sobre la intencionalidad de las políticas europeas en cuanto a la conciliación de la vida familiar y laboral, y estudiar, si las mismas, responden más a los compromisos adquiridos para alcanzar tasas de participación femenina (aumento del empleo y de la disponibilidad laboral), que a los objetivos de integración de la mujer en el mercado laboral y de mejora de la calidad del empleo y del bienestar. El trabajo a tiempo parcial suele estar considerado como un complemento de ingresos para las unidades familiares; se trata de un trabajo fundamentalmente ocupado por mujeres, con lo cual se puede afirmar que es causa de segmentación laboral para una parte importante de la población femenina.

Las investigaciones y los datos estadísticos demuestran que la única expectativa de empleo para una parte de la población activa es un trabajo a tiempo par- 
cial aunque ésta no sea su elección, más bien es una decisión forzada debido a no poder encontrar un trabajo a tiempo completo.

Es importante destacar, coincidiendo con los resultados del estudio de Arrazola et al. (2010), que los contratos a tiempo parcial son debidos en gran medida a factores institucionales, y sería muy conveniente que se promovieran políticas que impulsaran los factores efectivos que pudieran articular la conciliación de la vida familiar y laboral y las políticas de natalidad.

\section{Bibliografía}

Aragón Medina, J.; Cruces Aguilera, J. Martínez Poza, A. y Rocha Sánchez, F. (2012): El tiempo de trabajo y la jornada laboral en España, Ed. Comisiones Obreras, fundación 1.o de Mayo, Madrid. CEPES-Andalucía (2015): Informes estadísticos de la Economía Social. Central de Estadísticas de Economía Social. http://www.cepesandalucia.es/estadisticas/introduccion

Chell, E. (2007): «Social Enterprise and Entrepreneurship». International Small Business al, 25 (1), pp. 5-26.

Directiva 97/81/CE del Consejo de 15 de diciembre de 1997. Acuerdo marco sobre el trabajo a tiempo parcial concluido por la Unión de Confederaciones de la Industria y de Organizaciones Empresariales de Europa (UNICE), Centro Europeo de la Empresa Pública (CEEP) y Confederación Europea de Sindicatos (CES).

Durán, M.A. (2002): La contabilidad del tiempo. Ed. Azacanes.

Eurostat (2013): Datos de empleo, obtenidos de la European Labour Force Survey (EULFS).http://epp.eurostat.ec.europa.eu/portal/page/portal/employment_unemployment_lfs/data/main_tables.

- (2014): Labour Force Survey. Eurostat, Comisión Europea; http://epp.eurostat. ec.europa.eu/portal/page/portal/statistics/search_database

FARnÉ, E. (2003): Estudio sobre la calidad del empleo en Colombia. Oficina Regional para América Latina y el Caribe, Perú, OIT.

Fundación Europea (2010): Changes over time. First finding from the fith European Working Conditions Survey. Fundación Europea para la Mejora de las Condiciones de Vida y de Trabajo; http:// www.eurofound.europa.eu/pubdocs/2010/74/en/3/ EF1074EN.

Goerlich, J.M. (coord.) (2008): El tiempo de trabajo en la negociación colectiva. Ministerio de Trabajo e Inmigración, Colección Informes y Estudios, serie Relaciones Laborales, núm. 86.

GonzÁlez Begega, S. y Guillén Rodríguez, A.M. (2009): «La calidad del empleo en la Unión Europea. Debate político y construcción de indicadores», Revista del Ministerio de Trabajo e Inmigración, núm. 81, pp. 71-88.

Guzmán, A. y Trujillo, M.A. (2008): «Emprendimiento Social-Revisión de la Literatura». Estudios Gerenciales, vol. 24, n. ${ }^{\circ} 109$, pp. 105-125.

Harding, R (2004): «Social Enterprise: The New Economic Engine?». Business Strategy Review, 15 (4), pp. 39-43.

Instituto Nacional de Estadística (2014): Encuesta de Población Activa 2005-2012 microdatos; http://www.ine.es/prodyser/micro_epa.htm 
LeY 12/2001, de 9 de julio de 2001, de medidas urgentes de reforma del mercado de trabajo para el incremento del empleo y la mejora de su calidad; BOE núm. 164/2001, 10 de julio de 2001.

Martin, R. y Osberg, S. (2007): «Social Entrepreneurship: The case for definition». Stanford social innovation review, 5 (1), pp. 28-39.

Melián, A. y Campos, V. (2010): «Emprendedurismo y Economía Social como mecanismos de inserción sociolaboral en tiempos de crisis». REVESCO: revista de estudios cooperativos, (100), 43-67.

Moore, M. (2000): «Managing for Value: Organizational Strategy in Forprofit, Nonprofit, and Governmental Organizations». Nonprofit and Voluntary Sector Quaterly, 29, pp. 183-204.

Murphy, P.J. y Coombes, S.M. (2009): «A Model of social entrepreneurial Discovery». Journal of Business Ethics, 85, 325-336.

OCDE (1998): Perspectivas de empleo 1998, Ministerio de Trabajo y Asuntos Sociales, Madrid.

- (2010): "How good is part-time work», OECD Employment Outlook 2010: Moving beyond the jobs crisis, Paris.

- (2010): "How good is part-time work», OECD Employment Outlook 2010: Moving beyond the jobs crisis, Paris.

- (2013): Estadísticas de la OCDE. Disponible en: http://stats.oecd.org/Index.aspx\#

OIT (1994): «Convenio 175 sobre el trabajo a tiempo parcial» 81 Conferencia General de la OIT, Ginebra 1994; http:/www.ilo.org.

- (1999): Trabajo decente. Memoria del Director General a la 87. ${ }^{\text {a }}$ reunión de la Conferencia Internacional del Trabajo. Ginebra.

- (2006): Trabajo decente en las Américas: una agenda hemisférica, 2006-15 ; XVI Reunión Regional Americana, Brasilia, mayo de 2006.

- (2011): Data base of conditions of work and employment Laws, 11 de Julio de 2011; http:/www.ilo.org/dyn/travmain.home

Orden TIN/41/2011 de 18 de enero, por la que se desarrollan las normas de cotización a la Seguridad Social, Desempleo, Fondo de Garantía Salarial y Formación Profesional, contenidas en la Ley 39/2010, de 22 de diciembre, de Presupuestos Generales del Estado para el ańo 2011. B.O.E. núm. 17, jueves 20 de enero de 2011.

Pedrajas Moreno, A. (1994): «El trabajo a tiempo parcial», en F. Valdés Dal-Ré, La reforma del mercado laboral, Lex Nova, Valladolid, pp. 128-159.

Pérez Infante, J.I. (2006): Las estadisticas del mercado de trabajo en España; Colección Informes y Estudios. Serie Empleo, núm. 28. Ministerio de Trabajo y Asuntos Sociales.

Posso, C.M. (2010): «Calidad del empleo y segmentación laboral: un análisis para el mercado laboral colombiano 2001-2006». Desarrollo y sociedad, (65), 191-234.

Prieto, C. et al. (ed.) (2008): Nuevos tiempos del trabajo. Entre la flexibilidad de las empresas y las relaciones de género. CIS.

Ramos Martín, N.E. y Blázquez Cuesta, M. (2007): "Contrato de trabajo a tiempo parcial en los Países Bajos: ¿sólo para mujeres? Revista del Ministerio de Trabajo y Asuntos Sociales, núm. 66, pp. 143-159.

Real Decreto Legislativo 1/1995, de 24 marzo de 1995; Texto refundido de la Ley del Estatuto de los Trabajadores. BOE núm. 75/1995, 29 de marzo de 1995.

Real Decreto-Ley 3/2012, de 10 de febrero, de medidas urgentes para la reforma del mercado laboral. BOE núm. 36, sábado 11 de febrero de 2012. 
Real DeCReto-ley 16/2013, de 20 de diciembre, de medidas para favorecer la contratación estable y mejorar la empleabilidad de los trabajadores; BOE núm. 305, de 21 de diciembre de 2013.

Roberts, D. y Woods, C. (2005): «Changing the world on a shoestring: The concept of social entrepreneurship». University of Auckland Business Review, 7 (1), pp. 45-51.

Rubio, A., Aragón, A., Nicolás, C. y Pérez, A. (2014): "Emprendimiento Social: retos y oportunidades». Global Entrepreneurship. Monitor Informe GEM España 2014, 113-123.

SAntos, F.M. (2012). "A positive theory of social entrepreneurship». Journal of business ethics, 111(3), 335-351.

Segura, J.; Durán, F.; Toharia, L. y Bentolila, S. (1991): Análisis de la contratación Temporal en España, Ministerio de Trabajo y Seguridad Social, Madrid.

Segura, J. (2001): "La reforma del mercado de trabajo español: un panorama», Revista de Economia Aplicada, número 25, (Vol. IX), pp. 157-190.

Sirvent García del Valle, E. (2009): El empleo a tiempo parcial como herramienta para compatibilizar la flexibilidad laboral y la conciliación de la vida laboral y personal. Colección Estudios, núm. 217, Consejo Económico y Social España.

Social Enterprise Knowledge Network-SEKN (2006): Gestión efectiva de emprendimientos sociales: Lecciones estaraidas de empresas y organizaciones de la sociedad civil en Iberoamérica. Washintong, D.C.: Inter-America Development.

Sullivan, G.; Weerawarddena, J. y Carnegie, K. (2002): «Social Entrepreneurship: Towards conceptualization». International Journal of Nonprofit \& Voluntary Sector Marketing, 8 (1), 76.

Toharia, L. (2002): «El modelo español de contratación temporal»; Temas Laborales, núm. 64/2002, pp. 117-139.

Toharia, L. (dir.) (2005): El problema de la temporalidad en España: un diagnóstico; Colección Economía y Sociología del Trabajo, núm. 80, Ministerio de Trabajo y Asuntos Sociales, Madrid.

Van Bastelaer, A. y Hussmann, R. (2000): «Measurement of the quality of employment: Introduction and overview», paper presented at the Joint ece-Eurostat-Ilo Seminar on Measurement of the Quality of Employment, Geneva, May. 